\title{
An overview of the Oil Palm Empty Fruit Bunch (OPEFB) potential as reinforcing fibre in polymer composite for energy absorption applications
}

\author{
M.K. Faizi ${ }^{1,2, *}$, Shahriman A.B. ${ }^{1,2}$, M.S. Abdul Majid ${ }^{1}$, Shamsul B.M.T. ${ }^{3}, N g$ Y.G. ${ }^{3}$, S.N.

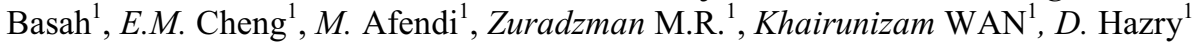 \\ ${ }^{1}$ School of Mechatronic Engineering, Universiti Malaysia Perlis, Pauh Putra Campus, 02600 Arau, \\ Perlis, Malaysia. \\ ${ }^{2}$ Motorsport Technology Unit, Universiti Malaysia Perlis, Pauh Putra Campus, 02600 Arau, Perlis, \\ Malaysia. \\ ${ }^{3}$ Faculty of Medicine and Health Science,Universiti Putra Malaysia, 43400 UPM Serdang, Selangor \\ Darul Ehsan.
}

\begin{abstract}
The oil palm empty fruit bunch (OPEFB) natural fibres were comprehensively reviewed to assess their potential as reinforcing materials in polymer composites for energy absorption during low-velocity impact. The typical oil palm wastes include trunks, fronds, kernel shells, and empty fruit bunches. This has a tendency to burden the industry players with disposal difficulties and escalates the operating cost. Thus, there are several initiatives have been employed to convert these wastes into value added products. The objective of this study is to review the potential of oil palm empty fruit bunch (OPEFB) as natural fibre polymer composite reinforcement to absorb the energy during low-velocity impact as another option for value added products. Initially, this paper reviewed the local oil palm waste issues. Previous research works on OPEFB polymer composite, and their mechanical characterization is appraised. Their potential for energy absorption in low-velocity impact application was also elaborated. The review suggests high potential applications of OPEFB as reinforcing materials in composite structures. Furthermore, it is wisely to utilize the oil palm biomass waste into a beneficial composite, hence, promotes the green environment.
\end{abstract}

\section{Introduction}

There has been a growing interest in recent years in finding fibre solutions for efficient and cheap energy absorbing composites. Among the numerous possibilities is using natural fibre to form polymer composite due to its eco-friendly and renewable nature. Natural

\footnotetext{
*Corresponding author: mkhairulfaizi@unimap.edu.my
} 
fibres offer various advantages such as low density, low cost, biodegradability, acceptable specific properties, better thermal and insulating properties and low energy consumption during processing [1]. Currently, the natural fibres in polymer composite that extremely explored are jute, kenaf, cotton, flax, and hemp. These natural fibres commonly use with matrices to provide better particular tensile strength, flexural strength, stiffness, and elongation at break [2]. Examples of matrices that widely used are thermoplastic polymer: polypropylene (PP); polyvinyl chloride (PVC); polyethylene (PE); and polystyrene (PS), thermosets polymers: phenolics; epoxies; isocyanates, and unsaturated polyesters.

The oil palm empty fruit bunch (OPEFB) as shown in Fig. 1 is a potential natural fibre to be explored. Recent studies conducted investigate the OPEFB reinforced polymer composite found to yield even better in characteristics [1], [3]-[7]. OPEFB is categorized as a palm oil industry waste which is generated from the oil extraction mills process.

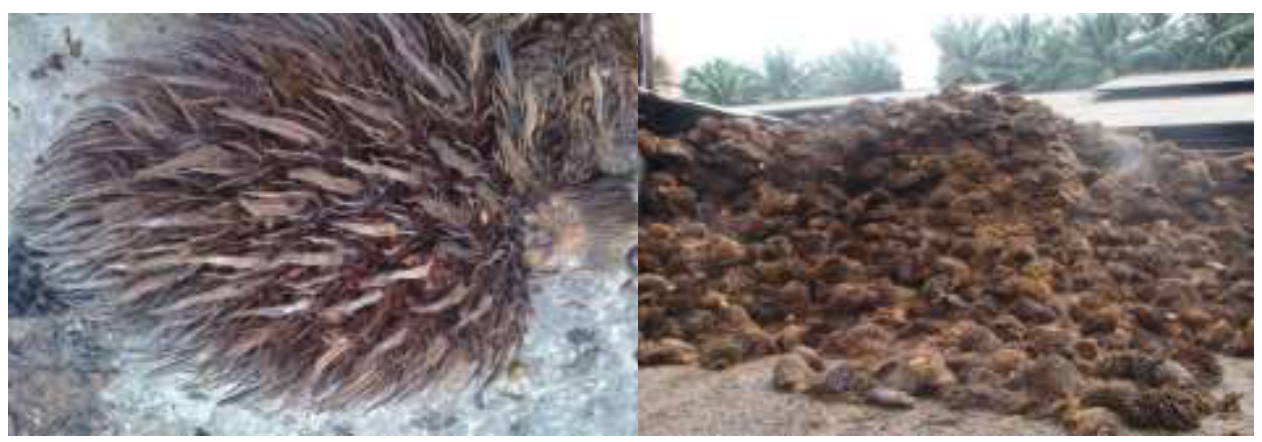

Fig. 1. The oil palm empty fruit bunch (OPEFB).

Malaysia is among the top most important oil palm producers in the world and experiencing a robust development in new plantations and palm oil mills through giant government companies (FELDA, FELCRA, and RISDA) and private estates (Guthrie, IOI Plantations, Genting Plantations, and Sime Darby). Fig. 2 shows the percentage of palm oil plantations ownership. Fig 3 on the other hand, demonstrate the expansion of palm oil cultivation area in Malaysia 1960 to 2014. The total area of oil palm cultivations by 2014 is 5.39 million hectares which private estates contribute a bigger percentage, $62 \%$.

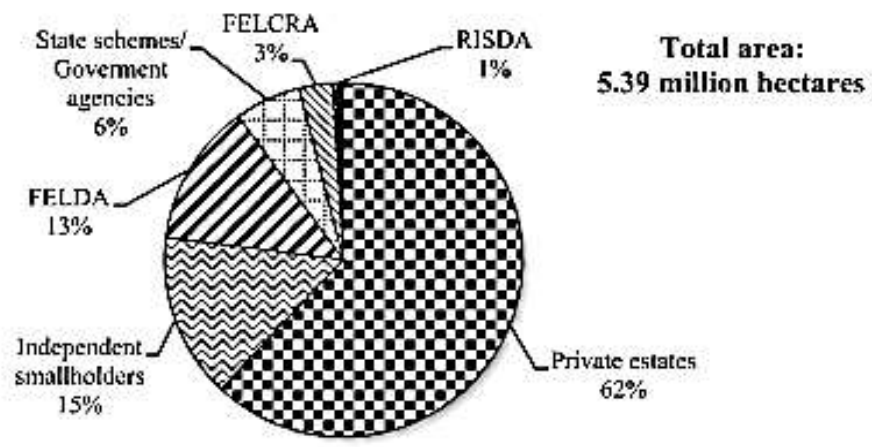

Fig. 2. Percentage of oil palm plantations ownership in 2014 [8].

The success of these oil palm plantation companies is strongly supported by responsible government agencies like the Malaysian Palm Oil Board (MPOB), Malaysian Palm Oil Council (MPOC), Palm Oil Research Institute of Malaysia (PORIM), and Forest Research Institute Malaysia (FRIM). This commodity plays a significant role in the Malaysia economic growth. 


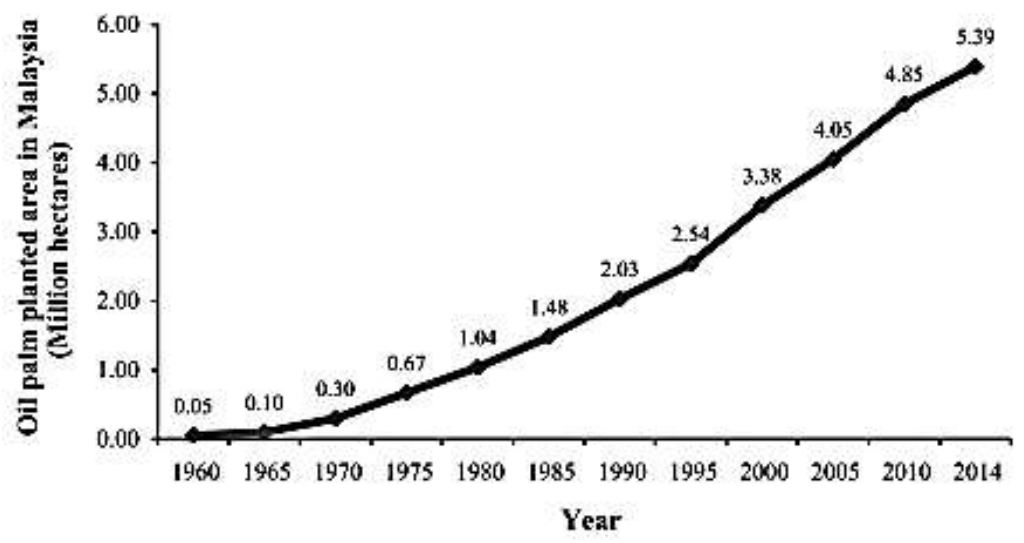

Fig. 3. Expansion of oil palm plantations cultivation in Malaysia area [8].

In palm oil industry, biomass wastes were generated by; [8] first, it comes from plantation routines, pruning and re-plantation work which produces wastes such as fronds and trunk. Second; wastes are also produced from oil extraction mills process such as oil palm empty fruit bunch (OPEFB) and mesocarp fibre. This abundance biomass wastes are a natural source of fibres and can be utilized as potential reinforcing materials in the polymer composite. However, this review will focus on OPEFB to investigate the capabilities of impact energy absorption applications due to its lack of downstream use. Unlike OPEFB, other oil palm wastes have established downstream use such as fronds and trunks were used for animal feedstock while kernel shells were used as fuel for the steam boiler in palm oil mills.

\section{Oil palm wastes issues}

The waste by-product from palm oil extraction process enormously could achieve $70-80$ million tons per annum [4]. In the palm oil mill, palm oil consists only $10 \%$ of the total biomass, while the rest (90\%) biomass are discarded as wastes [8]. This problem tends to burden the operators with disposal difficulties and escalates the operating cost.

To address the matter, these oil palm wastes were recycled in many applications. Among others; fronds and trunks were used as an animal feedstock [8], mesocarp turned into boiler fuel, kernel shells reused as road paving [9], an oil palm empty fruit bunch (OPEFB) transformed into soil conditioners [10], [11] and fiberboard [12]. However, the reused of OPEFB as soil conditioners still not of popular and there is still an enormous excessive waste yet to be handled. The steam from the sterilization process results in a high moisture content in the EFB; as high as $60 \%$, make it unsuitable usage as boiler fuel [12]. Eventually, burn them without any benefits is the only option opted by the farmers. Even worse, the production of OPEFB shows increasing trend with 7 million tons of waste produced in 2007 [8]. Thus, this research purpose is to utilize the OPEFB waste fully into a beneficial polymer composite as an efficient and cheap energy absorbing the material in composite structures.

Apart from its eco-friendly, renewable nature, cheap, low density, better thermal and insulating properties, the processes of converting OPEFB's fibre into composite promotes low energy consumption [1]. 


\section{The energy absorption in low-velocity impact}

The energy absorption in mechanics can be exhibited as the power to absorb in various forms, conditions, and directions of impact energy. In the case of a projectile impacts hits into a structure, the absorbed energy can be estimated by energy loss after impact and mathematically can be calculated through the integration of the impact force with the displacement plot [13]. Usually, when performing the impact test to examine the energy absorption, the results were presented in load-displacement curves. The energy absorption during the impact test is obtained by calculating the area under the load- displacement curve with the unit $\mathrm{Nm}$ (Joule) as shown in Eq. 1:

$$
E=\int_{0}^{\delta_{1}} P d \delta
$$

where $\delta$ is the crushing distance, $\mathrm{P}$ is the applied load and $\mathrm{E}$, the energy absorbed. However, the impact test result also can be presented in load-time curves. In fact, the loadtime curves are easier to obtain from an experimental sample [14]. Thus, another way to calculate the energy absorption is to multiply the load signal by the average velocity and integrate over the impact time. The energy absorbed at any instant during the impact on the specimen depicted as shown in Eq. 2:

$$
E=v_{\text {ave }}=\int_{0}^{t_{1}} P d t
$$

where $\mathrm{P}$ is the applied load, $\mathrm{v}_{\text {ave }}$ the average velocity and $\mathrm{E}$ is the energy absorbed by the specimen at a specified time. The value of energy is normalized by the mass of the crushed portion or by the crushed volume. Furthermore, the energy loss is also could be calculated as a function of the difference between the incident kinetic energy and residual kinetic energy of the projectile [15]. Specifically, using the notation in Fig. 4, absorbed energy is expressed as shown by Eq. 3:

$$
E_{a}=\frac{1}{2} m\left(v_{i}^{2}-v_{r}^{2}\right)
$$

where $\mathrm{Ea}$ is the absorbed energy, $\mathrm{m}$, Mass of the projectile, $\mathrm{v}_{\mathrm{i}}^{2}$, Incident velocity immediately before impact and $\mathrm{v}_{\mathrm{r}}^{2}$; Residual velocity immediately after impact.

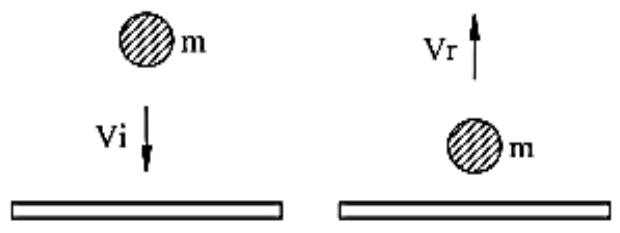

Fig. 4. Schematic view of a projectile impacting a structure [15].

Based on these formulae, the energy absorption is dependent on mass or load and projectile velocity. Usually, there are three types of velocity classifications in impact test: low velocity; high velocity; hyper velocity. However, this research is focusing on low-velocity impact condition. Low velocity impact occurs within $10 \mathrm{~m} / \mathrm{s}$ [16]-[27]. 


\section{The previous multidisciplinary OPEFB polymer reinforced composites studies}

Recently, several investigations and efforts have been employed to utilize the OPEFB for value added products such as bio-adsorbent, bio-oil, pulp, and activated carbon [4]. The OPEFBs were also explored on electrical, bio-energy, bio-resource, and chemistry field [28]-[34]. Nevertheless, the OPEFB is still not been fully explored as biodegradable polymer composites. The OPEFB viewed as a potential to be highlighted in polymer composite due to its several advantages such as uncomplicated processing, low in density, real strength, relatively high in hardness, and the most crucial is the nature biodegradation.

A flexural and tensile properties of polypropylene (PP) composite which reinforced by OPEFB fiber and fiberglass agents were studied by Rozman et al. [7]. The incorporation of OPEFB fibre into the PP matrix has resulted in the reduction of flexural and tensile strength. The flexural and tensile modulus was found to improved with increasing level of overall fibre content loading. Along with the trend that used of PP's plastic packaging beverage increased, the huge waste of plastic waste generated also growing. Therefore, the wastes of PP's plastic (wPP) are derived with EFB to form a composite material [3]. However, some modifications had been made to lower the interfacial tension between the matrix and EFB fibre filler. So that, the maleic anhydride polypropylene-g-polypropylene (MAPP) was chosen to providing compatibilizer or treating the surface or both. The composite is then going through the impact strength and thermal degradation test. Results indicated that addition MAPP improved the impact resistance and increased degradation temperature.

The polyurethane (PU) oil palm empty fruit bunch (EFB) composites have been produced by [1]. EFB fibres were used in the form of mats where it was treated with hexamethylene diisocyanate (HMDI) and toluene diisocyanate (TDI). The found that the PU-EFB composite had acceptable properties which were thought to be mostly influenced by the type of bonding produced. The tensile strength, tensile modulus, elongation at break, tensile toughness, flexural strength, flexural modulus, flexural toughness, and impact strength optimally up to $23 \mathrm{MPa}, 1.3 \mathrm{GPa}, 4.4 \%$, 4.5 Joule, $75 \mathrm{MPa}, 1.7 \mathrm{GPa}, 4.8$ Joule, 19 $\mathrm{j} / \mathrm{sq} . \mathrm{m}$ respectively. The EFB fibres and its cellulose have also been matrixes with polypropylene (PP) to investigate the mechanical properties [6]. The PP-EFB and PPcellulose gave a different performance in term of tensile strength, impact strength, and flexural modulus. The PP-cellulose performed better in all ways where the highest tensile strength is $35 \mathrm{Mpa}$, impact strength is $38 \mathrm{~J} / \mathrm{m}$, and flexural modulus is $4000 \mathrm{MPa}$ while the PP-EFB is $20 \mathrm{MPa}, 32 \mathrm{~J} / \mathrm{m}$, and $2700 \mathrm{MPa}$ respectively.

The EFB fibre also explored as a hybrid composite for widening its potential. The hybrid of EFB/jute fibres reinforced epoxy had ever been studied to investigate the mechanical performance [5]. This hybrid composite with a different layer of the mat was prepared: EFB-jute-EFB; jute-EFB-jute. Through the bending test, the jute-EFB-jute exhibited the best performance with flexural strength and modulus in $49 \mathrm{MPa}$ and $\quad 3.07$ GPa respectively. As a comparison, the EFB-jute-EFB flexural strength and modulus in 44.6 $\mathrm{MPa}$ and 2.68 GPa respectively.

\section{The OPEFB polymer reinforced composites potential for energy absorption application}

Though the studies regarding energy absorption on the OPEFB polymer reinforced composites initiated, there are lots of parameters remaining unexplored. The wider experimental works through various impact tests require to be done in order to provide the 
precise energy absorption characteristics of OPEFB. However, the previous experimental results revealed its potential especially through low velocity impact. Rozman et al., (2004) improved the impact strength of OPEFB from 8 to $20 \mathrm{j} / \mathrm{sq} . \mathrm{m}$ with the use of isocyanate treatment [1]. Khalid et al., (2008) increased the OPEFB impact strength from 32 to $38 \mathrm{~J} / \mathrm{m}$ by deriving its cellulose [6]. In the meantime, Nasution et al., (2015) successfully characterized the impact strength based on maleic anhydride polypropylene-gpolypropylene (MAPP). As a result, the impact strength achieved $34000 \mathrm{~J} / \mathrm{m}^{2}$ for the content of $8 \%$ of the MAPP [3].

The most encouraging experimental result of OPEFB polymer reinforced composite was published by Jawaid et al., (2010) [5]. They compared the performance on energy absorption between different composite materials. The impact tests were performed on different sequence of fibre mate sandwich arrangement such as pure epoxy, pure OPEB, OPEFB/jute/OPEFB, jute/OPEFB/jute, and pure jute and were fabricated by hand lay-up method. Table 1 shows the impact strength experimental result. Referring to the Table 1 , pure epoxy shows the weakest impact strength with $30.4 \mathrm{~J} / \mathrm{m}$ and followed by pure jute in a bottom two with $32 \mathrm{~J} / \mathrm{m}$. Meanwhile, jute/OPEFB/jute and OPEFB/jute/OPEFB shows the better result with $57 \mathrm{~J} / \mathrm{m}$ and $66.7 \mathrm{~J} / \mathrm{m}$ respectively. Impressively, the pure OPEFB composite shows the tremendous result with $92.7 \mathrm{~J} / \mathrm{m}$ of energy absorption capability. For this matter, Jawaid et al., claimed that the OPEFB fibre has higher fracture toughness compared to jute. It is because the OPEFB fibre is comprised of lignin, hemicellulose, and cellulose predominantly. Hence, the chemical composition during treatment and the architecture of cell wall gives the composite higher impact properties.

Table 1. The various composites fibre impact test result [5].

\begin{tabular}{|c|c|}
\hline Composites & Impact strength (J/m) \\
\hline Pure epoxy & 30.4 \\
\hline Pure OPEFB & 92.7 \\
\hline OPEFB/jute/OPEFB & 66.7 \\
\hline Jute/OPEFB/jute & 57 \\
\hline Pure jute & 32 \\
\hline
\end{tabular}

Based on the all findings from previous research in OPEFB polymer composite, there are huge potential for the energy absorption application on low velocity impact. These initial studies showed the positive experimental data in order to further investigation on OPEFB impact strength characteristic. Wider experimental parameters could be explored to discover the establish finding.

\section{Conclusions}

In this paper, the overview of OPEFB in multidisciplinary studies and the potential natural fibre polymer composite for energy absorption was elucidated. It reviewed the previous research regarding OPEFB composite development in the sense of methods, architectures, experiments, and results. However, this study was debated more on energy absorption of OPEFB polymer composite during low velocity impact. Based on the previous studies result, it's revealed the evidence that the OPEFB polymer composite had a potential in energy absorption applications. The local oil palm waste issue also had been discussed in this paper. With the oil palm empty fruit bunch (OPEFB) availability and disposal problem, it might boost the effort to convert them into a beneficial product. As a conclusion, the 
explorations of OPEFB reinforcing fibres in polymer composites suggest vast opportunity and encouraging towards promoting eco-products of the future.

The authors would like to be obliged to Universiti Malaysia Perlis (UniMAP) for providing laboratory facilities, Motorsport Technology Unit (MOTECH) UniMAP for providing financial assistance, and Universiti Putra Malaysia (UPM) as collaboration partnership.

\section{References}

1. H. D. Rozman, K. R. Ahmadhilmi, and A. Abubakar, "Polyurethane (PU) - Oil palm empty fruit bunch (EFB) composites: The effect of EFBG reinforcement in mat form and isocyanate treatment on the mechanical properties," Polym. Test., vol. 23, no. 5, pp. 559-565, 2004.

2. M. Talimi, "Characterization of natural fibre reinforced biodegradable composites," 2011.

3. H. Nasution, S. Pandia, Maulida, and M. S. Sinaga, "Impact Strength and Thermal Degradation of Waste Polypropylene (wPP)/Oil Palm Empty Fruit Bunch (OPEFB) Composites: Effect of Maleic Anhydride -g-polypropylene (MAPP) Addition," Procedia Chem., vol. 16, pp. 432-437, 2015.

4. R. Roslan, S. Zakaria, C. H. Chia, R. Boehm, and M. P. Laborie, "Physico-mechanical properties of resol phenolic adhesives derived from liquefaction of oil palm empty fruit bunch fibres," Ind. Crops Prod., vol. 62, pp. 119-124, 2014.

5. M. Jawaid, H. P. S. Abdul Khalil, and A. Abu Bakar, "Mechanical performance of oil palm empty fruit bunches/jute fibres reinforced epoxy hybrid composites," Mater. Sci. Eng. A, vol. 527, no. 29-30, pp. 7944-7949, 2010.

6. M. Khalid, C. T. Ratnam, T. G. Chuah, S. Ali, and T. S. Y. Choong, "Comparative study of polypropylene composites reinforced with oil palm empty fruit bunch fiber and oil palm derived cellulose," Mater. Des., vol. 29, no. 1, pp. 173-178, 2008.

7. H. D. Rozman, G. S. Tay, R. N. Kumar, A. Abusamah, H. Ismail, and Z. a M. Ishak, "Polypropylene \pm oil palm empty fruit bunch \pm glass ${ }^{\circledR}$ bre hybrid composites : a preliminary study on the flexural and tensile properties," Eur. Polym. J., vol. 37, no. 6, pp. 1283-1291, 2001.

8. M. F. Awalludin, O. Sulaiman, R. Hashim, and W. N. A. W. Nadhari, "An overview of the oil palm industry in Malaysia and its waste utilization through thermochemical conversion, specifically via liquefaction," Renew. Sustain. Energy Rev., vol. 50, pp. 1469-1484, 2015.

9. F. Sulaiman, N. Abdullah, H. Gerhauser, and A. Shariff, "An outlook of Malaysian energy, oil palm industry and its utilization of wastes as useful resources," Biomass and Bioenergy, vol. 35, no. 9, pp. 3775-3786, 2011.

10. S. Yusoff, "Renewable energy from palm oil - Innovation on effective utilization of waste," J. Clean. Prod., vol. 14, no. 1, pp. 87-93, 2006.

11. S. H. Shuit, K. T. Tan, K. T. Lee, and A. H. Kamaruddin, "Oil palm biomass as a sustainable energy source: A Malaysian case study," Energy, vol. 34, no. 9, pp. 12251235, 2009.

12. S. Prasertsan and P. Prasertsan, "Biomass residues from palm oil mills in Thailand: An overview on quantity and potential usage," Biomass and Bioenergy, vol. 11, no. 5, pp. 387-395, 1996.

13. L. Torre and J. M. Kenny, "Impact testing and simulation of composite sandwich structures for civil transportation," Compos. Struct., vol. 50, no. 3, pp. 257-267, 2000.

14. E. E. Hong, "Energy absorption of composite sandwich structures during low-velocity impact" 1999. 
15. H. Su, "Energy Absorption Capabilities of Composite Sandwich Panels under Blast Loads," 2011.

16. M. Akil Hazizan and W. J. Cantwell, "The low velocity impact response of foambased sandwich structures," Compos. Part B Eng., vol. 33, no. 3, pp. 193-204, 2002.

17. S. Heimbs, S. Heller, and P. Middendorf, "Simulation of Low Velocity Impact on Composite Plates with Compressive Preload," LS-DYNA Anwenderforum, pp. 11-24, 2008.

18. S. N. a Safri, M. T. H. Sultan, N. Yidris, and F. Mustapha, "Low Velocity and High Velocity Impact Test on Composite Materials - A review," Int. J. Eng. Sci., pp. 50-60, 2014.

19. U. Farooq and P. Myler, "Ply level failure prediction of carbon fibre reinforced laminated composite panels subjected to low velocity drop-weight impact," Acta Astronaut., vol. 102, pp. 169-177, 2014.

20. D. During, L. Weib, D. Stefaniak, N. Jordan, and C. Huhne, "Low-velocity impact response of composite laminates with steel and elastomer protective layer," Compos. Struct., vol. 134, pp. 18-26, 2015.

21. B. Yang, Z. Wang, L. Zhou, J. Zhang, and W. Liang, "Experimental and numerical investigation of interply hybrid composites based on woven fabrics and PCBT resin subjected to low-velocity impact," Compos. Struct., vol. 132, pp. 464-476, 2015.

22. M. Kathiresan and K. Manisekar, "Axial crush behaviours and energy absorption characteristics of aluminium and E-glass/epoxy over-wrapped aluminium conical frusta under low velocity impact loading," Compos. Struct., vol. 136, pp. 86-100, 2016.

23. H. Zarei, M. Fallah, G. Minak, H. Bisadi, and A. Daneshmehr, "Low velocity impact analysis of Fiber Metal Laminates ( FMLs ) in thermal environments with various boundary conditions," Compos. Struct., 2016.

24. V. Antonucci, F. Caputo, P. Ferraro, A. Langella, V. Lopresto, V. Pagliarulo, M. R. Ricciardi, A. Riccio, and C. Toscano, "Low velocity impact response of carbon fiber laminates fabricated by pulsed infusion: A review of damage investigation and semiempirical models validation," Prog. Aerosp. Sci., vol. 81, pp. 26-40, 2016.

25. P. Malekzadeh and M. Dehbozorgi, "Low velocity impact analysis of functionally graded carbon nanotubes reinforced composite skew plates," Compos. Struct., vol. 140, pp. 728-748, 2016.

26. E. Panettieri, D. Fanteria, and F. Danzi, "A sensitivity study on cohesive elements parameters: Towards their effective use to predict delaminations in low-velocity impacts on composites," Compos. Struct., vol. 137, pp. 130-139, 2016.

27. D. Nardi, L. Lampani, M. Pasquali, and P. Gaudenzi, "Detection of low-velocity impact-induced delaminations in composite laminates using Auto-Regressive models," Compos. Struct., 2016.

28. L. Tan, M. Wang, X. Li, H. Li, J. Zhao, Y. Qu, Y. M. Choo, and S. K. Loh, "Fractionation of oil palm empty fruit bunch by bisulfite pretreatment for the production of bioethanol and high value products," Bioresour. Technol., vol. 200, pp. 572-578, 2016.

29. N. Zulkiple, M. Y. Maskat, and O. Hassan, "Pretreatment of Oil Palm Empty Fruit Fiber (OPEFB) with Aquaeous Ammonia for High Production of Sugar," Procedia Chem., vol. 18, no. Mcls 2015, pp. 155-161, 2016.

30. S. X. Chin, C. H. Chia, S. Zakaria, Z. Fang, and S. Ahmad, "Ball milling pretreatment and diluted acid hydrolysis of oil palm empty fruit bunch (EFB) fibres for the production of levulinic acid," J. Taiwan Inst. Chem. Eng., vol. 52, pp. 85-92, 2015.

31. S. H. Chang, "An overview of empty fruit bunch from oil palm as feedstock for bio-oil production," Biomass and Bioenergy, vol. 62, pp. 174-181, 2014. 
32. O. Hassan, T. P. Ling, M. Y. Maskat, R. M. Illias, K. Badri, J. Jahim, and N. M. Mahadi, "Optimization of pretreatments for the hydrolysis of oil palm empty fruit bunch fiber (EFBF) using enzyme mixtures," Biomass and Bioenergy, vol. 56, no. 0, pp. 137-146, 2013.

33. Y. L. Chiew and K. Y. Cheong, "Growth of SiC nanowires using oil palm empty fruit bunch fibres infiltrated with tetraethyl orthosilicate," Phys. E Low-Dimensional Syst. Nanostructures, vol. 44, no. 10, pp. 2041-2049, 2012.

34. M. H. Ahmad, M. F. Dolmat, N. Bashir, H. Ahmad, and a. a. a. Jamil, "Effects of Oil Palm Empty Fruit Bunch Filler on the Electrical Tree Propagation in Silicone Rubber," APCBEE Procedia, vol. 3, no. May, pp. 147-153, 2012. 